\title{
Coordination of a Random Yield Supply Chain with a Loss-Averse Supplier
}

\author{
Jiarong Luo and Xu Chen \\ School of Management and Economics, University of Electronic Science and Technology of China, Chengdu 611731, China \\ Correspondence should be addressed to Xu Chen; xchenxchen@263.net
}

Received 23 February 2015; Revised 17 June 2015; Accepted 23 June 2015

Academic Editor: Dan Simon

Copyright (C) 2015 J. Luo and X. Chen. This is an open access article distributed under the Creative Commons Attribution License, which permits unrestricted use, distribution, and reproduction in any medium, provided the original work is properly cited.

\begin{abstract}
This paper investigates the coordination of a supply chain consisting of a loss-averse supplier and a risk-neutral buyer who orders products from the supplier who suffers from random yield to meet a deterministic demand. We derive the risk-neutral buyer's optimal order policy and the loss-averse supplier's optimal production policy under shortage-penalty-surplus-subsidy (SPSS) contracts. We also analyze the impacts of loss aversion on the loss-averse supplier's production decision making and find that the loss-averse supplier may produce less than, equal to, or more than the risk-neutral supplier. Then, we provide explicit conditions on which the random yield supply chain with a loss-averse supplier can be coordinated under SPSS contracts. Finally, adopting numerical examples, we find that when the shortage penalty is low, the buyer's optimal order quantity will increase, while the supplier's optimal production quantity will first decrease and then increase as the loss aversion level increases. When the shortage penalty is high, the buyer's optimal order quantity will decrease but the supplier's optimal production quantity will always increase as the loss aversion level increases. Furthermore, the numerical examples provide strong evidence for the view that SPSS contracts can effectively improve the performance of the whole supply chain.
\end{abstract}

\section{Introduction}

Random yield is a major cause of supply uncertainty which has been identified as one of the top three operation risks in a supply chain $[1,2]$. In the academic circle, supply chain management with random yield has attracted many researchers and how to hedge or share the random yield risk in a supply chain, in particular, has drawn an ever wider concern [3-5]. A recent paper by Inderfurth and Clemens [6] analyzed a buyer-supplier supply chain in which the buyer orders products from the supplier who suffers from random yield to meet a deterministic demand. In their paper, two operation scenarios are considered in terms of suppliers: with and without a second source (emergency procurement). Under each scenario, the optimal production quantity under centralized decision making and the buyer's optimal ordering quantity as well as the supplier's optimal production quantity under decentralized decision making are derived. They found that the double marginalization effect also exists under a simple wholesale price contract (WHP), whereas the supply chain coordination can be achieved with an overproduction risk sharing contract (also called surplus subsidy contract in some literature, e.g., Yan and Liu [7]) or a penalty contract in the case of without emergency procurement. However, a wholesale price contract is enough to achieve the channel coordination if there is an emergency procurement option for the supplier.

Like many supply chain models in literature, decision makers in Inderfurth and Clemens [6] paper are assumed to be risk-neutral and to maximize profit $[8,9]$. However, from previous experimental studies of managerial decisionmaking under uncertainty, it can be observed that the managers' decision-making behaviors were consistent with loss aversion and deviated from maximizing (expected) profit [10-13]. Loss aversion, originated from Kahneman and Tversky's Prospect Theory [14], refers to people's strong preference of avoiding losses to acquiring the same-sized gains [15-17]. It has been well studied in fields such as organizational behavior, finance, marketing, and economics. In recent years, operations management with loss aversion has gradually attracted great attention in the academic circle [15]. 
Motivated by the observations above, we in this paper revisit the similar problem as Inderfurth and Clemens [6] and consider the case where the supplier is loss-averse, while the buyer is still risk-neutral. As a common phenomenon in reality, such case has attracted many researchers [17, 18]. However, most of them consider solely the demand uncertainty while neglecting the supply uncertainty, especially the relevant risks caused by random yield. Our major contributions to the literature are as follows.

(1) We develop supply chain models incorporating both shortage penalty (SP) contract and a surplus subsidy (SS) contract (we will call it SPSS contract in this paper) as well as a loss-averse supplier. Our paper casts light on the impact of loss-averse on decision making and performance of the supply chain in the context of random yield.

(2) We derive analytical solutions to the risk-neutral buyer's optimal order policy and loss-averse supplier's optimal production policy. Meanwhile, we explore the impact of loss aversion on the loss-averse supplier's production decision-making and obtain many interesting results.

(3) We also provide explicit conditions on which the random yield supply chain with a loss-averse supplier can be coordinated and demonstrate that the results of Inderfurth and Clemens [6] are special cases in our paper.

This paper is organized as follows. The next section reviews related work in the literature. We restate problem description and notations in Section 3. In Section 4, we investigate the loss-averse supplier's optimal production policy and the impact of loss aversion on the loss-averse supplier's decision-making. The risk-neutral buyer's optimal order policy is derived in Section 5. We explore the conditions for supply chain coordination in Section 6 and present numerical examples in Section 7. Finally, we conclude the paper in Section 8.

\section{Literature Review}

Our paper touches two areas of supply chain management research: with random yield and with loss-averse agents. Although both areas have been extensively studied, most of the previous studies are in separate contexts. Karlin [19], motivated by uncertain harvest yield in agriculture, was a pioneer in investigating single-period inventory problem with random yield. Later, an increasing number of researchers also took interest in this field, but the early research mainly focused on developing various random yield models to analyze the inventory/production control problem (e.g., lot sizing). Yano and Lee [20] provided a detailed review on these researches. Along with the popularity of supply chain management in academic circle [21, 22], how to manage random yield risk in a supply chain context has attracted a vast amount of researchers' concern. Among these studies, some investigated the issue of procurement and production management problems, such as the studies of Keren [23], Li et al. [24], He and Zhang [3], Wang [25], and Kaki et al. [26]; others extended their exploration into the issue of supply chain coordination, such as the studies of Yan and Liu [7], Li et al. [4], and Tang and Kouvelis [5]. For more detailed literature review on this field, readers may refer to $\mathrm{He}$ and Zhang [3] and Li et al. [4]. These papers have comprehensively studied the management of the random yield risk from different views. However, the decision makers in these studies are usually supposed to be risk-neutral.

There is an intensive literature on supply chain management with loss-averse agents, too. The majority of these studies focus on the single-period inventory problem, also known as the newsvendor problem. Eeckhoudt et al. [27] are the first to study the loss-averse newsvendor problem by considering the case that the newsvendor is allowed to obtain additional quantity when the demand exceeds the initial order. Their analyses show that a loss-averse newsvendor will order strictly less than a risk-neutral one. Since then, the lossaverse newsvendor models and the impact of loss aversion on the ordering decision have been discussed under various settings, for example, without shortage cost [11], with shortage cost [28], with substitutable products [29], with credit insurance and capital constraint [18], with customer returns [30] and with asymmetric information [31]. However, only a few of these papers are involved in the supply chain coordination with loss aversion. Wang and Webster [32] investigated the role of a gain/loss- (GL-) sharing provision in mitigating the loss aversion effect in a risk-neutral manufacturer and a lossaverse retailer system. They, in particular, show that a GLsharing-and-buyback (GLB) credit provision can achieve the channel coordination. Chen et al. [16] considered a supply chain consisting of a risk-neutral supplier and a loss-averse retailer. They analyzed the optimal policies both of the retailer and supplier as well as the coordination conditions of the supply chain under option contracts. These studies consider the situations where the attitudes of decision makers are loss-averse to the associated risks. In addition, Chiu and Choi [17] reviewed the literatures that adopt the meanvariance models to depict the utility function of loss-averse agents in supply chain risk management. However, they only consider the demand uncertainty while neglecting the supply uncertainty, especially the relevant risks caused by random yield.

The papers by Giri [33], Liu et al. [34], and X. Li and Y. J. Li [15] are the rare ones to consider both loss aversion and random yield. Giri [33] studied how the loss aversion affects the dual sourcing strategies of a risk-averse retailer who can order from two suppliers, the cheaper one with random yield and the reliable but more expensive one. Liu et al. [34] also investigated a loss-averse newsvendor model with random yield and stochastic demand. They obtained the optimal order quantity and analyzed the impacts of loss aversion. Giri [33] and Liu et al. [34] were still confined to consider loss aversion from the angle of the newsvendor problem. Considering multiplicative and additive random yield risks, X. Li and Y. J. Li [15] investigated the lot-sizing problem in a random yield production system. However, they just considered the production problem while not considering the buyer's order problem, let alone the channel coordination issue. To the best of our knowledge, there has not been any published paper that has addressed such issue so far. Hence, our study shed new light on the management of supply chain with random yield and loss aversion. 


\section{Problem Description and Notations}

Consider a supply chain consisting of a loss-averse supplier and a risk-neutral buyer who orders products from the loss-averse supplier to meet a deterministic demand $d$ in a single-period selling season. The loss-averse supplier is subject to a random yield risk in the production process. We in this study depict the random yield with a stochastically proportional yield model, which has been frequently used in the literatures (see Karlin [19]); that is, for an input Q, the output is TQ; $T(T \in[0,1])$ is the random variable with the density function $\varphi(t)$ and the cumulative distribution $\Phi(t)$ and $E(T)=\mu$. Note that here the random yield rate $T$ is independent of the input size $Q$.

In this paper, we study the case where the buyer is comparatively more powerful and provides the supplier with a contract composed of shortage penalty (SP) and surplus subsidy (SS). Under SPSS contract, the supplier will be punished for underdelivery, whereas the supplier can obtain subsidy (compensation) for overproduction (the amount that exceeds the order); that is, the buyer has to pay for every unit produced by the supplier. Let $q$ be the number of the buyer's order and let $Q$ be the number of the input level of the supplier. The buyer pays the supplier $w$ per unit of the order while compensates $w_{1}\left(w_{1}<w\right)$ for each unit that exceeds the order if the production yield is high. If the production yield is low, the buyer charges penalty $s_{1}$ for each unit ordered but not fulfilled. The production cost of the supplier is $c$ per unit and the buyer sells the end-products at a unit price $p$. To simplify the analysis, we normalize the production cost and salvage value of the end-product as well as all other costs to zero. Note that we assume in this paper that the supplier obtains finished goods only from the initial regular production; that is, there is no emergency production or other outside source to meet the buyer's order.

We further assume that utility function of the riskneutral buyer is equal to its expected profit function and the loss-averse supplier has the following piecewise-linear utility function which is widely adopted in literatures (see Schweitzer and Cachon [11]; Chen et al. [16]; Wang and Webster [32]). Consider

$$
U(\pi)= \begin{cases}\pi & \text { if } \pi \geq 0 \\ \gamma \pi & \text { if } \pi<0,\end{cases}
$$

where $\gamma \geq 1$ is the supplier's loss aversion coefficient, which means that people are more sensitive to losses than to samesized gains. Higher values of $\gamma$ correspond to higher level of loss aversion, and $\gamma=1$ implies that the supplier is riskneutral. Throughout the paper, we assume that all parties' reference level is zero.

Besides, symmetric information is assumed; that is, at the beginning of the game, both firms hold the same information, which means all parameters and rules are known by each firm. To avoid uninteresting case, we assume $p>w>$ $c / \mu>w_{1}$. Superscripts " $b$ " (buyer) and " $s$ " (supplier) are adopted to differentiate between the profit of the buyer and that of the supplier, and " $c$ " is adopted to denote profit of the integrated supply chain. Note that $x^{+}=\max (0, x)$.
In addition, the proofs of all lemmas and theorems will be given in the appendix.

\section{Loss-Averse Supplier's Optimal Production Policy}

In this section, we explore the optimal production policy of the loss-averse supplier under a SPSS contract. The profit function of the supplier, denoted by $\pi^{s}(Q)$, is

$$
\begin{aligned}
& \pi^{s}(Q) \\
& = \begin{cases}\pi_{1}^{s}(t ; Q ; q)=w t Q-s_{1}(q-t Q)-c Q & \text { if } t Q<q \\
\pi_{2}^{s}(t ; Q ; q)=w q+w_{1}(t Q-q)-c Q & \text { if } t Q \geq q .\end{cases}
\end{aligned}
$$

Then the expected profit function of the supplier, denoted by $E\left[\pi^{s}(Q)\right]$, is

$$
\begin{aligned}
E\left[\pi^{s}(Q)\right]= & \int_{0}^{q / Q}\left(w-w_{1}+s_{1}\right)(t Q-q) \varphi(t) d t+w q \\
& +w_{1}(\mu Q-q)-c Q .
\end{aligned}
$$

We discuss the breakeven quantities of the realized yield rate below. Let $t$ be the realized yield rate.

Case 1. If $t<q / Q$, then, from the supplier's profit function (2), $\pi_{1}^{s}(t ; Q ; q)=w t Q-s_{1}(q-t Q)-c Q ;$ let $\pi_{1}^{s}\left(t_{1} ; Q ; q\right)=0$; we get $t_{1}=\left(s_{1} q+c Q\right) /\left(w+s_{1}\right) Q$. Since $\pi_{1}^{s}(t ; Q ; q)$ is strictly increasing in $t$, so if $Q \leq(w / c) q$, then $\pi_{1}^{s}(t ; Q ; q)<0$ for $t<t_{1}$ and $\pi_{1}^{s}(t ; Q ; q)>0$ for $t_{1}<t<q / Q$; if $Q>(w / c) q$, then $\pi_{1}^{s}(t ; Q ; q)<0$ for $t<q / Q$.

Case 2. If $t \geq q / Q$, then, from the supplier's profit function (2), $\pi_{2}^{s}(t ; Q ; q)=w q+w_{1}(t Q-q)-c Q ;$ let $\Pi_{2}^{s}\left(t_{2} ; Q ; q\right)=0$; we get $t_{2}=\left(c Q-\left(w-w_{1}\right) q\right) / w_{1 Q}$. Since $\pi_{2}^{s}(t ; Q ; q)$ is also strictly increasing in $t$, so if $Q \leq(w / c) q$, then $\pi_{2}^{s}(t ; Q ; q)>0$ for $t \geq q / Q$; if $Q>(w / c) q$, then $\pi_{2}^{s}(t ; Q ; q)<0$ for $q / Q<t<t_{2}$ and $\pi_{2}^{s}(t ; Q ; q)>0$ for $t>t_{2}$. lemma.

Combining the above two parts, we can get the following

Lemma 1. If $Q \leq(w / c) q$, then $\pi^{s}(Q) \geq 0$ for $t \in\left(\left(s_{1} q+\right.\right.$ $\left.c Q) /\left(w+s_{1}\right) Q, 1\right)$ and $\pi^{s}(Q)<0$ for $t \in\left(0,\left(s_{1} q+c Q\right) /(w+\right.$ $\left.\left.s_{1}\right) Q\right)$; if $Q>(w / c) q$, then $\pi^{s}(Q) \geq 0$ for $t \in((c Q-$ $\left.\left.\left(w-w_{1}\right) q\right) / w_{1} Q, 1\right)$ and $\pi^{s}(Q)<0$ for $t \in(0,(c Q-(w-$ $\left.\left.\left.w_{1}\right) q\right) / w_{1} Q\right)$.

Lemma 1 provides the conditions under which the lossaverse supplier's profit will be negative or positive according to the realized yield rate. It shows that, whatever the production quantity is, there are only one breakeven threshold $\left(t_{1}=\left(s_{1} q+c Q\right) /\left(w+s_{1}\right) Q\right.$ for $Q \leq(w / c) q$ and $t_{2}=$ $\left(c Q-\left(w-w_{1}\right) q\right) / w_{1 Q}$ for $\left.Q>(w / c) q\right)$, which means that the supplier will always face losses as long as the realized yield rate is low.

According to the above results, the loss-averse supplier's expected utility function, denoted by $E\left[U\left(\pi^{s}(Q)\right)\right]$, can be written as 


$$
E\left[U\left(\pi^{s}(Q)\right)\right]=E\left[\pi^{s}(Q)\right]+(\gamma-1) \times \begin{cases}\int_{0}^{t_{1}} \pi_{1}^{s}(t ; Q ; q) \varphi(t) d t, & \text { if } Q \leq \frac{w}{c} q \\ \int_{0}^{q / Q} \pi_{1}^{s}(t ; Q ; q) \varphi(t) d t+\int_{q / Q}^{t_{2}} \pi_{2}^{s}(t ; Q ; q) \varphi(t) d t, & \text { if } Q>\frac{w}{c} q .\end{cases}
$$

The loss-averse supplier's expected utility can be regarded as the expected profit plus its biased losses related to the expected profit. The loss-averse supplier's decision problem is

$$
\max _{Q>0} E\left[U\left(\pi^{s}(Q)\right)\right]
$$

Theorem 2. $E\left[U\left(\pi^{s}(Q)\right)\right]$ is concave in $Q ;$ let $Q^{*}(q)$ denote the supplier's optimal production quantity for a given $q$. If $Q^{*}(q) \leq$ $(w / c) q$, then $Q^{*}(q)$ is solved by the following equation:

$$
\begin{aligned}
& \int_{0}^{q / Q^{*}(q)}\left(w-w_{1}+s_{1}\right) t \varphi(t) d t+(\gamma-1) \\
& \quad \cdot \int_{0}^{\left(s_{1} q+c Q^{*}(q)\right) /\left(w+s_{1}\right) Q^{*}(q)}\left[\left(w+s_{1}\right) t-c\right] \varphi(t) d t=c \\
& \quad-w_{1} \mu .
\end{aligned}
$$

If $Q^{*}(q)>(w / c) q$, then $Q^{*}(q)$ is solved by the following equation:

$$
\begin{aligned}
& \int_{0}^{q / Q^{*}(q)} \gamma\left(w-w_{1}+s_{1}\right) t \varphi(t) d t \\
& \quad+(\gamma-1) \int_{0}^{\left(c Q^{*}(q)-\left(w-w_{1}\right) q\right) / w_{1} Q^{*}(q)}\left(w_{1} t-c\right) \varphi(t) d t \\
& \quad=c-w_{1} \mu .
\end{aligned}
$$

Theorem 2 characterizes the supplier's best response function (optimal production quantity), $Q^{*}(q)$, for the buyer's any given order quantity $q$. Due to the loss-averse attitude of the supplier to the random yield, the response functions to $Q \leq(w / c) q$ and $Q>(w / c) q$ are different. We can further derive the following lemma from Theorem 2 .

Lemma 3. $Q^{*}(q)$ is linearly increasing in $q$.

Lemma 3 indicates that the optimal production quantity of the loss-averse is linearly increasing in the risk-neutral buyer's order quantity. It shows that the results of $\mathrm{He}$ and Zhang [3] and Wang [25] who assume that both the buyer and supplier are risk-neutral do hold in our model. Therefore, we define

$$
Q^{*}(q)= \begin{cases}\delta_{\gamma 1} q & \text { if } \delta_{\gamma 1} \leq \frac{w}{c} \\ \delta_{\gamma 2} q & \text { if } \delta_{\gamma 2}>\frac{w}{c}\end{cases}
$$

Then, from (6), we can get that the linear coefficient $\delta_{\gamma 1}$ satisfies

$$
\begin{aligned}
& \int_{0}^{1 / \delta_{\gamma 1}}\left(w-w_{1}+s_{1}\right) t \varphi(t) d t \\
& \quad+(\gamma-1) \int_{0}^{s_{1} /\left(w+s_{1}\right) \delta_{\gamma 1}+c /\left(w+s_{1}\right)}\left[\left(w+s_{1}\right) t-c\right] \varphi(t) d t \\
& \quad=c-w_{1} \mu,
\end{aligned}
$$

and, from (7), the linear coefficient $\delta_{\gamma 2}$ satisfies

$$
\begin{aligned}
& \int_{0}^{1 / \delta_{\gamma 2}} \gamma\left(w-w_{1}+s_{1}\right) t \varphi(t) d t \varphi(t) d t \\
& \quad+(\gamma-1) \int_{0}^{c / w_{1}-\left(w-w_{1}\right) / w_{1} \delta_{\gamma 2}}\left(w_{1} t-c\right) \varphi(t) d t \\
& \quad=c-w_{1} \mu .
\end{aligned}
$$

As a special case, if the supplier is risk-neutral $(\gamma=1)$, from (9) and (10), we can get that the linear coefficient $\delta_{1}$ satisfies $\int_{0}^{1 / \delta_{1}}\left(w-w_{1}+s_{1}\right) t \varphi(t) d t=c-w_{1} \mu$. Thus, the impact of risk aversion on the optimal production policy of the supplier can be characterized in the following theorem.

Theorem 4. (1) If $\int_{0}^{s_{1} /\left(w+s_{1}\right) \delta_{\gamma 1}+c /\left(w+s_{1}\right)}\left[\left(w+s_{1}\right) t-c\right] \varphi(t) d t>0$, then $\delta_{\gamma 1}<\delta_{1}$ and $d \delta_{\gamma 1} / d \gamma>0$. If $\int_{0}^{s_{1} /\left(w+s_{1}\right) \delta_{\gamma 1}+c /\left(w+s_{1}\right)}[(w+$ $\left.\left.s_{1}\right) t-c\right] \varphi(t) d t=0$, then $\delta_{\gamma 1}=\delta_{1}$ and $d \delta_{\gamma 1} / d \gamma=0$. If $\int_{0}^{s_{1} /\left(w+s_{1}\right) \delta_{\gamma 1}+c /\left(w+s_{1}\right)}\left[\left(w+s_{1}\right) t-c\right] \varphi(t) d t<0$, then $\delta_{\gamma 1}>\delta_{1}$ and $d \delta_{\gamma 1} / d \gamma<0$.

(2) If $\int_{0}^{1 / \delta_{\gamma 2}}\left(w-w_{1}+s_{1}\right) t \varphi(t) d t+\int_{0}^{c / w_{1}-\left(w-w_{1}\right) / w_{1} \delta_{\gamma 2}}\left(w_{1} t-\right.$ c) $\varphi(t) d t>0$, then $\delta_{\gamma 2}<\delta_{1}$ and $d \delta_{\gamma_{2}} / d \gamma>0$. If $\int_{0}^{1 / \delta_{\gamma 2}}(w-$ $\left.w_{1}+s_{1}\right) t \varphi(t) d t+\int_{0}^{c / w_{1}-\left(w-w_{1}\right) / w_{1} \delta_{\gamma 2}}\left(w_{1} t-c\right) \varphi(t) d t=0$, then $\delta_{\gamma^{2}}=\delta_{1}$ and $d \delta_{\gamma 2} / d \gamma=0$. If $\int_{0}^{1 / \delta_{\gamma^{2}}}\left(w-w_{1}+s_{1}\right) t \varphi(t) d t+$ $\int_{0}^{c / w_{1}-\left(w-w_{1}\right) / w_{1} \delta_{\gamma 2}}\left(w_{1} t-c\right) \varphi(t) d t<0$, then $\delta_{\gamma 2}>\delta_{1}$ and $d \delta_{\gamma 2} / d \gamma<0$.

Theorem 4 shows that when the supplier is loss-averse the linear coefficient $\delta_{\gamma 1}\left(\delta_{\gamma 2}\right)$ will be smaller than, equal to, or bigger than that of the risk-neutral $\delta_{1}$. It indicates that when the yield is random the loss-averse supplier may produce less than, equal to, or more than the risk-neutral supplier under the SPSS contract.

Next, we investigate the impacts of the price/cost on the linear coefficient $\delta_{\gamma i}(i=1,2)$.

Lemma 5. $\delta_{\gamma i}(i=1,2)$ is increasing in $w$ and $s_{1}$ while decreasing in $c$. 
Lemma 5 suggests that the higher the wholesale price $w$ or the penalty for per unit $s_{1}$ or the smaller the production $\operatorname{cost} c$ is, the bigger the linear coefficient $\delta_{\gamma i}(i=1,2)$ will be.

\section{Risk-Neutral Buyer's Optimal Order Policy}

We now turn our attention to the optimal order policy of the risk-neutral buyer. Assuming that the buyer decides to order units $q$ to meet the deterministic market demand $d$ according to the realization of the supplier's yield rate, then the riskneutral buyer's expected profit, denoted by $E\left[\pi^{b}(q)\right]$, is

$$
\begin{aligned}
E\left[\pi^{b}(q)\right]= & p E \min \left(T Q^{*}, d\right)+s_{1} E\left(q-T Q^{*}\right)^{+} \\
& -w E \min \left(T Q^{*}, q\right)-w_{1} E\left(T Q^{*}-q\right)^{+} .
\end{aligned}
$$

The first two terms are the expected revenue from sales and penalty the supplier has to pay for the shortage, respectively. The last two terms are the costs incurred by purchasing the amount up to the order and the amount that exceeds the order, respectively. The above equation can be rewritten as

$$
\begin{aligned}
E\left[\pi^{b}(q)\right]= & \int_{0}^{d / Q^{*}} p\left(t Q^{*}-d\right) \varphi(t) d t \\
& -\int_{0}^{q / Q^{*}}\left(w+s_{1}-w_{1}\right)\left(t Q^{*}-q\right) \varphi(t) d t \\
& +p d-w q-w_{1}\left(\mu Q^{*}-q\right)
\end{aligned}
$$

The risk-neutral buyer solves the following problem:

$$
\max _{q>0} E\left[\pi^{b}(q)\right] \text {. }
$$

Taking into account $Q^{*}(q)=\delta_{\gamma i} q\left(i=1\right.$ if $\delta_{\gamma i} \leq w / c$, otherwise $i=2$ ), we can get

$$
\begin{aligned}
& E\left[\pi^{b}(q)\right] \\
& =\int_{0}^{d / \delta_{\gamma i} q} p\left(t \delta_{\gamma i} q-d\right) \varphi(t) d t \\
& \quad-\int_{0}^{1 / \delta_{\gamma i}}\left(w+s_{1}-w_{1}\right)\left(t \delta_{\gamma i} q-q\right) \varphi(t) d t+p d \\
& \quad-w q-w_{1}\left(\mu \delta_{\gamma i} q-q\right) .
\end{aligned}
$$

And then we derive the following theorem.

Theorem 6. $E\left[\pi^{b}(q)\right]$ is concave in $q$, and $q^{*}$ satisfies the following equation:

$$
\begin{aligned}
& \int_{0}^{d / \delta_{\gamma i} q^{*}} p t \delta_{\gamma i} \varphi(t) d t \\
& \quad-\int_{0}^{1 / \delta_{\gamma i}}\left(w+s_{1}-w_{1}\right)\left(t \delta_{\gamma i}-1\right) \varphi(t) d t \\
& \quad=w+w_{1}\left(\mu \delta_{\gamma i}-1\right),
\end{aligned}
$$

where $i=1$ if $\delta_{\gamma i} \leq w / c$, otherwise $i=2$.
Theorem 6 shows that the buyer's optimal order quantity $\left(q^{*}\right)$ depends on $p, w, w_{1}, s_{1}$, and the distribution of yield rate. From the above analysis, we can see that the optimal production quantity of the loss-averse suppler should be $Q^{*}=$ $\delta_{\gamma i} q^{*}\left(i=1\right.$ if $\delta_{\gamma i} \leq w / c$, otherwise $\left.i=2\right)$ if the risk-neutral buyer's optimal order quantity is $q^{*}$.

Inderfurth and Clemens [6] provided clear evidence for the existence of the double marginalization effect in the case of random yield and deterministic demand under the WHP. They also demonstrated that a surplus subsidy or a penalty contract can coordinate supply chains and provided the conditions on which the supply chain coordination can be achieved under each contract. Based on Inderfurth and Clemens's study, we have derived and analyzed the optimal policies of the risk-neutral buyer and the loss-averse supplier under SPSS contracts in this section. Next, we will discuss the conditions on which the random yield supply chain with a loss-averse supplier can be coordinated under SPSS contracts.

\section{Supply Chain Coordination}

Here we begin with studying the optimization problem of the integrated supply chain. Specifically, we assume that the integrated system is controlled by a large and risk-neutral firm. If the production quantity under the controlled firm is $Q^{c}$, then the integrated supply chain's expected profit, denoted by $\Pi^{c}\left(Q^{c}\right)$, is

$$
E\left[\Pi^{c}\left(Q^{c}\right)\right]=p \min \left(T Q^{c}, d\right)-c Q^{c} .
$$

The terms above refer to the expected revenue and the production cost, respectively. The above equation can be rewritten as

$$
E\left[\Pi^{c}\left(Q^{c}\right)\right]=\int_{0}^{d / Q^{c}} p\left(t Q^{c}-d\right) \varphi(t) d t+p d-c Q^{c} .
$$

Then, the integrated supply chain solves the following problem:

$$
\max _{Q^{c}>0} E\left[\Pi^{c}\left(Q^{c}\right)\right] .
$$

Theorem 7. $E\left[\Pi^{c}\left(Q^{c}\right)\right]$ is concave in $Q^{c}$, and $Q^{c *}$ satisfies the following equation:

$$
\int_{0}^{d / Q^{c *}} t \varphi(t) d t=\frac{c}{p} .
$$

Next, we explore the conditions on which the supply chain can be coordinated under SPSS contracts. Supply chain coordination can be achieved if the members can be motivated to take the same action as integrated supply chain requires (as in the integrated case) [35]. We assume that the risk-neutral buyer is comparatively more powerful in this paper. In such context, the supply chain coordination will be achieved if the risk-neutral buyer set contract parameters and order quantity based on the supplier's loss aversion level to motivate the supplier to produce in accordance with the decision of the integrated supply chain; that is, the loss-averse supplier should produce $Q^{c *}$. Therefore, replacing $Q^{*}$ with $Q^{c *}$ and $q^{*}$ with $d$ of Theorem 2 , we can get Theorem 8 . 
Theorem 8. The decentralized supply chain can be coordinated with shortage-penalty-surplus-subsidy contract when (1) $w \geq c Q^{c *} / d$ and $\int_{0}^{d / Q^{c *}}\left(w-w_{1}+s_{1}\right) t \varphi(t) d t+(\gamma-$ 1) $\int_{0}^{\left(s_{1} d+c Q^{c *}\right) /\left(w+s_{1}\right) Q^{c *}}\left[\left(w+s_{1}\right) t-c\right] \varphi(t) d t=c-w_{1} \mu$; or (2) $w<c Q^{c *} / d$ and $\int_{0}^{d / Q^{c *}} \gamma\left(w-w_{1}+s_{1}\right) t \varphi(t) d t+(\gamma-$ 1) $\int_{0}^{\left(c Q^{c *}-\left(w-w_{1}\right) d\right) / w_{1} Q^{c *}}\left(w_{1} t-c\right) \varphi(t) d t=c-w_{1} \mu$ is satisfied.

It can be observed form Theorem 8 that the coordination condition is closely related to the wholesale price $w$. From Theorem 8, we can see that when $\gamma=1$ and $s_{1}=0$, the coordination condition changes as $w+(p /(c / \mu)-1) w_{1}=p$. Besides, when $\gamma=1$ and $w_{1}=0$, the condition is $w+s_{1}=p$. It indicates that the results of Inderfurth and Clemens [6] are special cases in our paper.

When there is coordination for the supply chain, its total expected profit is always not smaller than that of the baseline case without coordination. It is clear that, by varying the contract parameters $w, w_{1}$, and $s_{1}$ according to Theorem 8 , the allocation of the supply chain profit between the buyer and the supplier will be achieved in many different ways. Compared with the noncoordinating scenario, there is always a Pareto improvement with the coordination scenario; that is, neither the supplier's nor the buyer's profit decreases and at least one firm is strictly better off. Thus, the buyer should aim at coordination so that both firms will see increase in their profits.

\section{Numerical Examples}

In the above sections, we adopt a generalized yield distribution to make our results more applicable. In this section, in order to make it more intuitive and intelligible, we suppose that the yield rate follows a uniform distribution with the mean yield rate $\mu=0.6$ and perform the numerical examples to analyze the impacts of loss aversion and some system parameters on the decisions and performances of the supply chain. The parameters are set as follows: $c=4, w=8$, and $p=15$. We consider a base example with $w_{1}=1$, $s_{1}=0, \gamma=3, d=100$, and $T \sim U(0.2,1.0)$. To conduct the comparison, we change the focal parameter and fix other parameters of the base case. The results are shown in Figures $1-6$.

To analyze the impacts of loss aversion on the buyer's optimal order quantity and the supplier's optimal production quantity, we first consider four different loss aversion levels: $\gamma=1, \gamma=2, \gamma=3, \gamma=4$, and $\gamma=5$ with $s_{1}=0$ and $s_{1}=3$. The optimal policies of the buyer and the supplier are plotted in Figures 1 and 2, respectively. From Figures 1 and 2, we find that the shortage penalty $s_{1}$ is a crucial parameter that affects the sensitivity of the two firms' optimal policies to the loss aversion level. More specifically, as $\gamma$ increases, the buyer's optimal order quantity will decrease when $s_{1}$ is high, while it will increase when $s_{1}$ is low. Meanwhile, for the supplier, as $\gamma$ increases, its optimal production quantity will increase when $s_{1}$ is high and will first decrease and then increase when $s_{1}$ is low, which further verifies Theorem 4 ; that is, the loss-averse

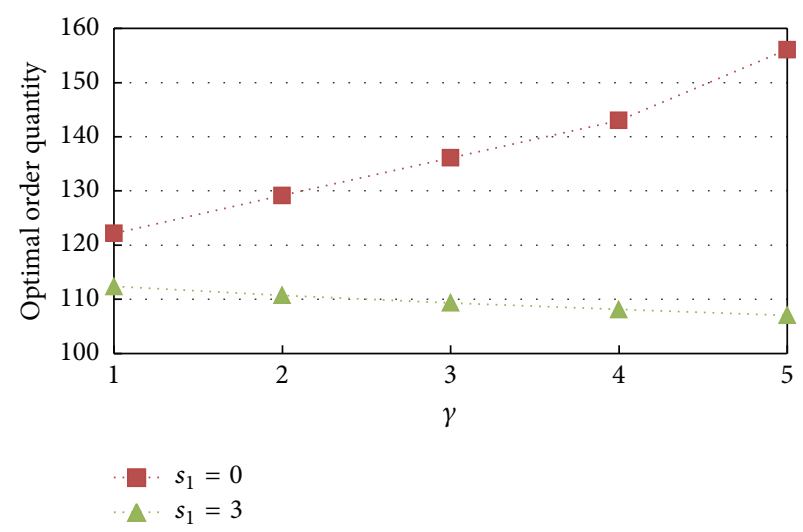

FIGURE 1: Plot of the buyer's optimal order quantity with $\gamma$ with different $s_{1}$.

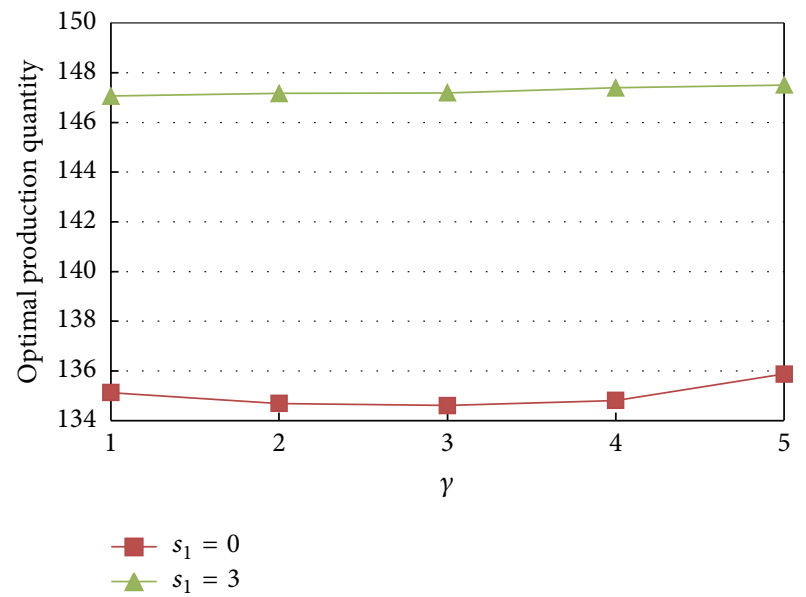

FigUre 2: Plot of the supplier's optimal production quantity with $\gamma$ with different $s_{1}$.

supplier may produce less than, equal to, or more than the risk-neutral supplier under SPSS contracts.

Next, we consider four different loss aversion levels: $\gamma=1$, $\gamma=2, \gamma=3, \gamma=4$, and $\gamma=5$ with $w_{1}=1$ and $w_{1}=3$. The optimal policies of the buyer and the supplier are plotted in Figures 3 and 4, respectively. Figures 3 and 4 show that the surplus subsidy $w_{1}$ poses only a limited influence on the sensitivity of the two firms' optimal policies to the loss aversion level. We find that in the two cases of $w_{1}$, as $\gamma$ increases, the buyer's optimal order quantity will increase, while the supplier's optimal production quantity first decreases and then increases. Moreover, Figures 1-4 show that the buyer is more sensitive to the supplier's loss aversion than the supplier.

To analyze the impacts of the surplus subsidy $w_{1}$ on the two firms' optimal policies, we consider four different surplus subsidy values: $w_{1}=1, w_{1}=2.5, w_{1}=4$, and $w_{1}=5.5$. The optimal policies of the buyer and the supplier with different $w_{1}$ are plotted in Figure 5. From Figure 5, we find that both the buyer's optimal order quantity and the supplier's optimal production quantity will increase as $w_{1}$ increases. It indicates that when the supplier is loss-averse, a bigger surplus subsidy 


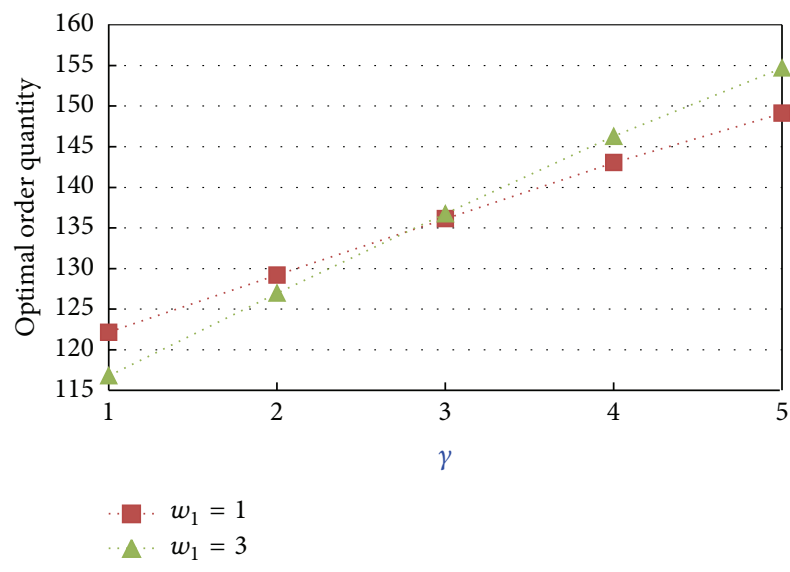

FIGURE 3: Plot of the buyer's optimal order quantity with $\gamma$ with different $w_{1}$.

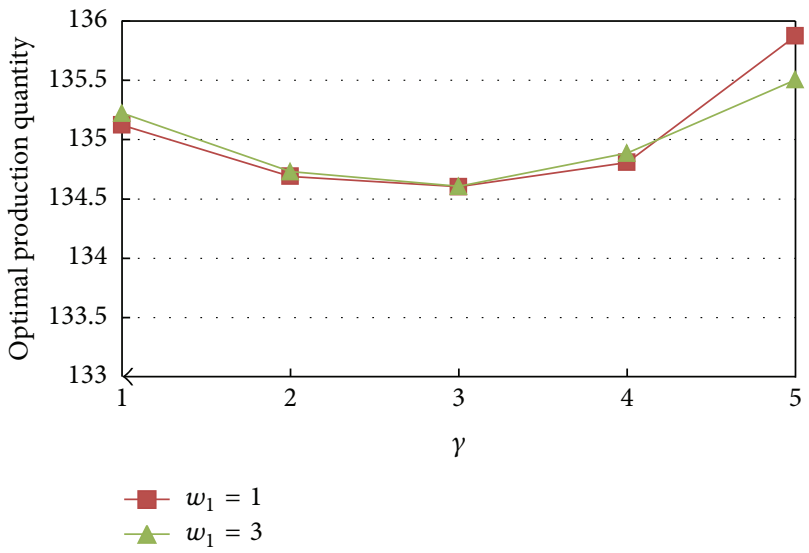

FIGURE 4: Plot of the supplier's optimal production quantity with $\gamma$ with different $w_{1}$.

$w_{1}$ will lead the buyer to order more and the supplier to produce more.

To analyze the impacts of the shortage penalty $s_{1}$ on the two firms' optimal policies, we consider four different shortage penalty value $s_{1}=0, s_{1}=1, s_{1}=2$ and $s_{1}=3$. The optimal policies of the buyer and the supplier with different $w_{1}$ are plotted in Figure 6. From Figure 6, we find that as $s_{1}$ increases, the buyer's optimal order quantity will decrease but the supplier's optimal production will increase. It indicates that when the supplier is loss-averse, a bigger shortage penalty $s_{1}$ will lead the buyer to order less but the supplier to produce more.

Table 1 illustrates the impacts of random yield and loss aversion on supply chain performance as well as the changes in the expected profit of the supplier, the buyer, and the whole supply chain after the introduction of SPSS contracts. In Table $1, \pi_{\mathrm{WHP}}^{s}, \pi_{\mathrm{WHP}}^{b}$, and $\Pi_{\mathrm{WHP}}\left(\Pi_{\mathrm{WHP}}=\pi_{\mathrm{WHP}}^{s}+\pi_{\mathrm{WHP}}^{b}\right)$, respectively, stand for the expected profit of the supplier, the buyer, and the whole supply chain under wholesale price contracts, while $\pi_{\mathrm{SPSS}}^{s}, \pi_{\mathrm{SPSS}}^{b}$, and $\Pi_{\mathrm{SPSS}}\left(\Pi_{\mathrm{SPSS}}=\pi_{\mathrm{SPSS}}^{s}+\pi_{\mathrm{SPSS}}^{b}\right)$ stand for the expected profit of the supplier, the buyer, and the whole supply chain under SPSS contracts. $\Pi_{c}$ stands for

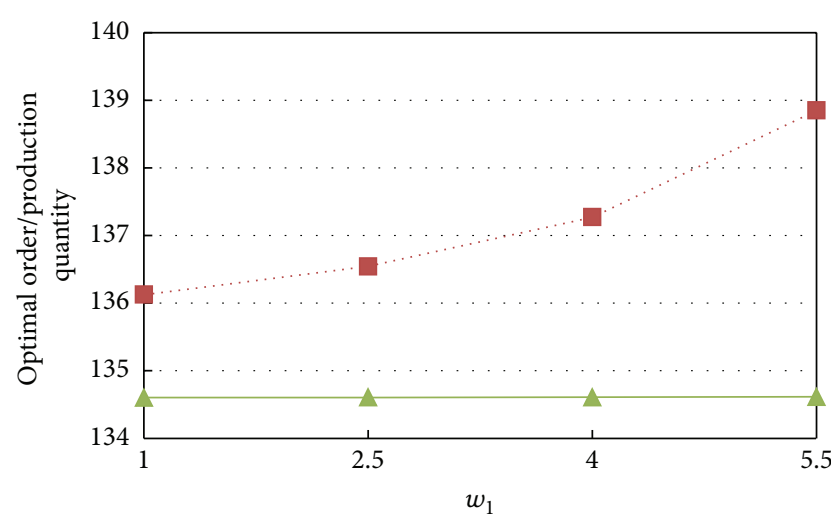

Buyer

- Supplier

Figure 5: Plot of the buyer's optimal order quantity and the supplier's optimal production quantity with $w_{1}$.

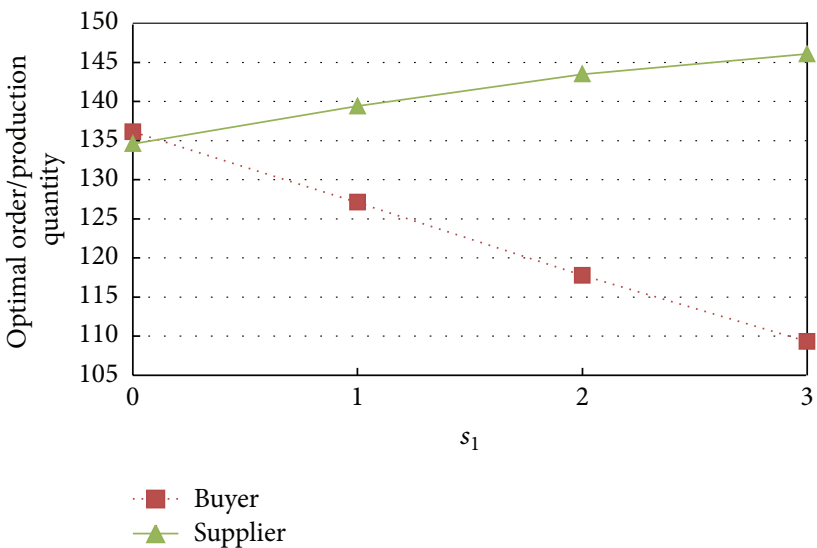

FIGURE 6: Plot of the buyer's optimal order quantity and the supplier's optimal production quantity with $s_{1}$.

TABLE 1: Expected profit under the WHP and the SPSS contract with different yield rate variance and loss aversion level when $w=9$ and $w_{1}=5$.

\begin{tabular}{lcccccccc}
\hline$T(a, b)$ & $\gamma$ & $\pi_{\mathrm{WHP}}^{s}$ & $\pi_{\mathrm{WHP}}^{b}$ & $\Pi_{\mathrm{WHP}}$ & $\pi_{\mathrm{SPSS}}^{s}$ & $\pi_{\mathrm{SPSS}}^{b}$ & $\Pi_{\mathrm{SPSS}}$ & $\Pi_{c}$ \\
\hline \multirow{3}{*}{$(0.2,1)$} & 2 & 120.0 & 325.4 & 445.4 & 118.3 & 422.1 & 540.4 & 594.1 \\
& 3 & 107.7 & 302.6 & 410.3 & 89.9 & 409.2 & 499.1 & 594.1 \\
& 4 & 99.0 & 297.6 & 396.6 & 65.8 & 403.3 & 469.1 & 594.1 \\
\hline \multirow{3}{*}{$(0.22,0.98)$} & 2 & 133.6 & 342.5 & 476.1 & 124.1 & 431.4 & 555.5 & 612.4 \\
& 3 & 117.1 & 326.8 & 443.9 & 94.8 & 420.9 & 515.7 & 612.4 \\
& 4 & 105.5 & 318.1 & 423.6 & 71.95 & 414.6 & 486.5 & 612.4 \\
\hline \multirow{2}{*}{$(0.24,0.96)$} & 2 & 139.4 & 354.9 & 494.3 & 129.9 & 440.9 & 570.8 & 630.4 \\
& 4 & 126.4 & 341.6 & 468.0 & 104.3 & 430.9 & 535.2 & 630.4 \\
& 4 & 112.2 & 325.1 & 437.3 & 75.88 & 424.4 & 500.2 & 630.4 \\
\hline
\end{tabular}

the expected profit of the integrated supply chain. Table 1 shows that the expected profit of all parties will increase as the yield rate variance decreases. Meanwhile, it also shows that the expected profit of all parties will decrease as the supplier's loss aversion level increases. More importantly, from Table 1, 
we can see that SPSS contracts can effectively improve the whole supply chain performance though the supplier's expected profit may be smaller under WHP contracts than that of under SPSS contracts. Nevertheless, under SPSS contracts, the expected profit of the whole supply chain without coordination is still smaller than that of with coordination, which indicates that the coordination is desirable.

\section{Conclusion and Future Research}

This paper probes into how the loss aversion affects the supply chain management and on what conditions the supply chain coordination can be achieved with a shortage-penaltysurplus-subsidy contract in the case of random yield. We develop supply chain models by assuming that the lossaverse supplier has a piecewise-linear utility function and derive the risk-neutral buyer's optimal order quantity and loss-averse supplier's optimal production quantity. Our work reveals that there's also a linear relationship between the buyer's order quantity and the supplier's production quantity. Through model comparison between loss-averse and riskneutral suppliers, we find that when the yield is random the loss-averse supplier will produce less than, equal to, or more than the risk-neutral supplier under the shortagepenalty-surplus-subsidy contract. Then, we provide explicit conditions on which the random yield supply chain with a loss-averse supplier can be coordinated and point out that the results of Inderfurth and Clemens [6] are special cases in our paper. Finally, the impacts of loss aversion and some system parameters on the decision and performances of the supply chain are analyzed by adopting numerical examples. Our study shed new light on the management of supply chain with random yield.

Similar to any other models previously published in the literature, the present model in our paper is also based on some assumptions. For example, our model assumes that the supplier is loss aversion, while the buyer is risk-neutral; we have to acknowledge that the buyer may be loss-averse; hence, a natural extension of our work can consider the problem when the buyer is also loss-averse. In addition, the case where both the random yield and stochastic demand are considered will be studied in the future. Finally, more general supply chains such as multiperiod models and multiple supplier and multiple buyer models should be examined.

\section{Appendix}

Proof of Theorem 2. From (4), if $Q \leq(w / c) q(q \geq(c / w) Q)$, then we know that

$$
\begin{aligned}
& E\left[U\left(\pi^{s}(Q)\right)\right]=(\gamma-1) \\
& \quad \cdot \int_{0}^{\left(s_{1} q+c Q\right) /\left(w+s_{1}\right) Q}\left[\left(w+s_{1}\right) t Q-s_{1} q-c Q\right] \varphi(t) d t \\
& \quad+\int_{0}^{q / Q}\left(w-w_{1}+s_{1}\right)(t Q-q) \varphi(t) d t+w q \\
& \quad+w_{1}(\mu Q-q)-c Q .
\end{aligned}
$$

So, we get

$$
\begin{aligned}
& \frac{d E\left[U\left(\pi^{s}(Q)\right)\right]}{d Q} \\
& =\int_{0}^{q / Q}\left(w-w_{1}+s_{1}\right) t \varphi(t) d t \\
& \quad+(\gamma-1) \int_{0}^{\left(s_{1} q+c Q\right) /\left(w+s_{1}\right) Q}\left[\left(w+s_{1}\right) t-c\right] \varphi(t) d t \\
& \quad-c+w_{1} \mu, \\
& \frac{d^{2} E\left[U\left(\pi^{s}(Q)\right)\right]}{d Q^{2}} \\
& =-\left(w-w_{1}+s_{1}\right) \frac{q^{2}}{Q^{3}} \varphi\left(\frac{q}{Q}\right) \\
& \quad-(\gamma-1) \frac{s_{1}^{2} q^{2}}{\left(w+s_{1}\right) Q^{3}} \varphi\left(\frac{s_{1} q+c Q}{\left(w+s_{1}\right) Q}\right)<0 .
\end{aligned}
$$

In addition, if $Q>(w / c) q(q \geq(c / w) Q)$, then we get

$$
\begin{gathered}
E\left[U\left(\pi^{s}(Q)\right)\right]=(\gamma-1) \\
\cdot \int_{0}^{\left(c Q-\left(w-w_{1}\right) q\right) / w_{1 Q}}\left[w q+w_{1}(t Q-q)-c Q\right] \\
\cdot \varphi(t) d t w q+\int_{0}^{q / Q} \gamma\left(w-w_{1}+s_{1}\right)(t Q-q) \\
\cdot \varphi(t) d t+w q+w_{1}(\mu Q-q)-c Q .
\end{gathered}
$$

Similarly, we get

$$
\begin{aligned}
& \frac{d E\left[U\left(\pi^{s}(Q)\right)\right]}{d Q} \\
& =\int_{0}^{q / Q} \gamma\left(w-w_{1}+s_{1}\right) t \varphi(t) d t \\
& \quad+(\gamma-1) \int_{0}^{\left(c Q-\left(w-w_{1}\right) q\right) / w_{1} Q}\left(w_{1} t-c\right) \varphi(t) d t \\
& \quad-c+w_{1} \mu, \\
& \frac{d^{2} E\left[U\left(\pi^{s}(Q)\right)\right]}{d Q^{2}} \\
& =-\gamma\left(w-w_{1}+s_{1}\right) \frac{q^{2}}{Q^{3}} \varphi\left(\frac{q}{Q}\right) \\
& \quad-(\gamma-1) \frac{\left(w-w_{1}\right)^{2} q^{2}}{w_{1} Q^{3}} \varphi\left(\frac{c Q-\left(w-w_{1}\right) q}{w_{1} Q}\right) \\
& <0 ;
\end{aligned}
$$

that is, $E\left[U\left(\pi^{s}(Q)\right)\right]$ is concave in $Q$, and a unique production quantity $Q^{*}$ which maximizes $E\left[U\left(\pi^{s}(Q)\right)\right]$ exists. Let $d E\left[U\left(\pi^{s}(Q)\right)\right] / d Q=0$ for the case of $q \geq(c / w) Q$ and $q<(c / w) Q$; we can derive (6) and (7), respectively. 
Proof of Lemma 3. From (6), letting

$$
\begin{aligned}
& K_{1}\left(q, Q^{*}(q)\right)=\int_{0}^{q / Q^{*}(q)}\left(w-w_{1}+s_{1}\right) t \varphi(t) d t-c \\
& +w_{1} \mu+(\gamma-1) \\
& \quad \cdot \int_{0}^{\left(s_{1} q+c Q^{*}(q)\right) /\left(w+s_{1}\right) Q^{*}(q)}\left[\left(w+s_{1}\right) t-c\right] \varphi(t) d t,
\end{aligned}
$$

we have

$$
\begin{aligned}
& \frac{\partial K_{1}}{\partial q}=\left(w-w_{1}+s_{1}\right) \frac{q}{\left[Q^{*}(q)\right]^{2}} \varphi\left(\frac{q}{Q^{*}(q)}\right) \\
& +(\gamma-1) \frac{s_{1}^{2} q}{\left(w+s_{1}\right) Q^{*}(q)} \varphi\left(\frac{s_{1} q+c Q^{*}(q)}{\left(w+s_{1}\right) Q^{*}(q)}\right) \\
& \frac{\partial K_{1}}{\partial Q^{*}(q)}=-\left(w-w_{1}+s_{1}\right) \frac{q^{2}}{\left[Q^{*}(q)\right]^{3}} \varphi\left(\frac{q}{Q^{*}(q)}\right) \\
& -(\gamma-1) \frac{s_{1}^{2} q^{2}}{\left(w+s_{1}\right)\left[Q^{*}(q)\right]^{2}} \\
& \cdot \varphi\left(\frac{s_{1} q+c Q^{*}(q)}{\left(w+s_{1}\right) Q^{*}(q)}\right)
\end{aligned}
$$

By the implicit function theorem, we can see

$$
\begin{gathered}
\frac{d Q^{*}(q)}{d q}=-\frac{\partial K_{1} / \partial q}{\partial K_{1} / \partial Q^{*}(q)}=\frac{Q^{*}(q)}{q}>0, \\
\frac{d^{2} Q^{*}(q)}{d^{2} q}=\frac{q d Q^{*}(q) / d q-Q^{*}(q) d q / d q}{q^{2}}=0 .
\end{gathered}
$$

Besides, from (7), letting

$$
\begin{aligned}
& K_{2}\left(q, Q^{*}(q)\right)=\int_{0}^{q / Q^{*}(q)} \gamma\left(w+s_{1}-w_{1}\right) t \varphi(t) d t \\
& \quad+(\gamma-1)
\end{aligned}
$$

$$
\begin{aligned}
& \cdot \int_{0}^{\left(c Q^{*}(q)-\left(w-w_{1}\right) q\right) / w_{1} Q^{*}(q)}\left(w_{1} t-c\right) \varphi(t) d t-c \\
& +w_{1} \mu,
\end{aligned}
$$

we get

$$
\begin{aligned}
& \frac{\partial K_{2}}{\partial q}=\gamma\left(w+s_{1}-w_{1}\right) \frac{q}{\left[Q^{*}(q)\right]^{2}} \varphi\left(\frac{q}{Q^{*}(q)}\right) \\
& +(\gamma-1) \frac{\left(w-w_{1}\right)^{2} q}{w_{1} Q^{*}(q)} \\
& \cdot \varphi\left(\frac{c Q^{*}(q)-\left(w-w_{1}\right) q}{w_{1} Q^{*}(q)}\right), \\
& \frac{\partial K_{2}}{\partial Q^{*}(q)}=-\gamma\left(w+s_{1}-w_{1}\right) \frac{q^{2}}{\left[Q^{*}(q)\right]^{3}} \varphi\left(\frac{q}{Q^{*}(q)}\right) \\
& \left.-(\gamma-1) \frac{\left(w-w_{1}\right)^{2} q^{2}}{w_{1}\left[Q^{*}(q)\right]^{2}}\right) \\
& \cdot \varphi\left(\frac{c Q^{*}(q)-\left(w-w_{1}\right) q}{w_{1} Q^{*}(q)}\right) .
\end{aligned}
$$

By the implicit function theorem, we also can see $d Q^{*}(q) / d q=-\left(\partial K_{2} / \partial q\right) /\left(\partial K_{2} / \partial Q^{*}(q)\right)=Q^{*}(q) / q>0$, and $d^{2} Q^{*}(q) / d^{2} q=\left(q d Q^{*}(q) / d q-Q^{*}(q) d q / d q\right) / q^{2}=0$. So, $Q^{*}(q)$ is linearly increasing in $q$.

Proof of Theorem 4. From (9), set

$$
\begin{aligned}
& L\left(\gamma, \delta_{\gamma 1}\right)=(\gamma-1) \\
& \quad \cdot \int_{0}^{s_{1} /\left(w+s_{1}\right) \delta_{\gamma 1}+c /\left(w+s_{1}\right)}\left[\left(w+s_{1}\right) t-c\right] \varphi(t) d t \\
& \quad+\int_{0}^{1 / \delta_{\gamma 1}}\left(w-w_{1}+s_{1}\right) t \varphi(t) d t-c+w_{1} \mu .
\end{aligned}
$$

By the implicit function theorem, we get

$$
\frac{d \delta_{\gamma 1}}{d \gamma}=-\frac{\partial L / \partial \gamma}{\partial L / \partial \delta_{\gamma 1}}=\frac{\int_{0}^{s_{1} /\left(w+s_{1}\right) \delta_{\gamma 1}+c /\left(w+s_{1}\right)}\left[\left(w+s_{1}\right) t-c\right] \varphi(t) d t}{\left(1 / \delta_{\gamma 1}^{3}\right)\left(w-w_{1}+s_{1}\right) \varphi\left(1 / \delta_{\gamma 1}\right)+(\gamma-1)\left(s_{1}^{2} /\left(w+s_{1}\right) \delta_{\gamma 1}^{3}\right) \varphi\left(s_{1} /\left(w+s_{1}\right) \delta_{\gamma 1}+c /\left(w+s_{1}\right)\right)}
$$

Comparing (9) with $\int_{0}^{1 / \delta_{1}}\left(w-w_{1}+s_{1}\right) t \varphi(t) d t=c-w_{1} \mu$, we have the following.

(1) If $\int_{0}^{s_{1} /\left(w+s_{1}\right) \delta_{\gamma 1}+c /\left(w+s_{1}\right)}\left[\left(w+s_{1}\right) t-c\right] \varphi(t) d t>0$, then $\delta_{\gamma 1}<\delta_{1}$ and $d \delta_{\gamma 1} / d \gamma>0$. If $\int_{0}^{s_{1} /\left(w+s_{1}\right) \delta_{\gamma 1}+c /\left(w+s_{1}\right)}[(w+$ $\left.\left.s_{1}\right) t-c\right] \varphi(t) d t=0$, then $\delta_{\gamma 1}=\delta_{1}$ and $d \delta_{\gamma 1} / d \gamma=0$. If $\int_{0}^{s_{1} /\left(w+s_{1}\right) \delta_{\gamma 1}+c /\left(w+s_{1}\right)}\left[\left(w+s_{1}\right) t-c\right] \varphi(t) d t<0$, then $\delta_{\gamma 1}>\delta_{1}$ and $d \delta_{\gamma 1} / d \gamma<0$.
From (9), set

$$
\begin{aligned}
& L\left(\gamma, \delta_{\gamma^{2}}\right) \\
& \quad=\int_{0}^{1 / \delta_{\gamma^{2}}} \gamma\left(w-w_{1}+s_{1}\right) t \varphi(t) d t \\
& \quad+(\gamma-1) \int_{0}^{c / w_{1}-\left(w-w_{1}\right) / w_{1} \delta_{\gamma 2}}\left(w_{1} t-c\right) \varphi(t) d t \\
& \quad-c+w_{1} \mu .
\end{aligned}
$$


Then, we get

$$
\frac{d \delta_{\gamma 2}}{d \gamma}=-\frac{\partial L / \partial \gamma}{\partial L / \partial \delta_{\gamma 2}}=\frac{\int_{0}^{1 / \delta_{\gamma^{2}}}\left(w-w_{1}+s_{1}\right) t \varphi(t) d t+\int_{0}^{c / w_{1}-\left(w-w_{1}\right) / w_{1} \delta_{\gamma^{2}}}\left(w_{1} t-c\right) \varphi(t) d t}{\left(\gamma / \delta_{\gamma 2}^{3}\right)\left(w-w_{1}+s_{1}\right) \varphi\left(1 / \delta_{\gamma 2}\right)+(\gamma-1)\left(\left(w-w_{1}\right)^{2} / w_{1} \delta_{\gamma 1}^{3}\right) \varphi\left(c / w_{1}-\left(w-w_{1}\right) / w_{1} \delta_{\gamma 2}\right)} .
$$

Comparing (10) with $\int_{0}^{1 / \delta_{1}}\left(w-w_{1}+s_{1}\right) t \varphi(t) d t=c-w_{1} \mu$, we have the following.

(2) If $\int_{0}^{1 / \delta_{\gamma 2}}\left(w-w_{1}+s_{1}\right) t \varphi(t) d t+\int_{0}^{c / w_{1}-\left(w-w_{1}\right) / w_{1} \delta_{\gamma^{2}}}\left(w_{1} t-\right.$ c) $\varphi(t) d t>0$, then $\delta_{\gamma_{2}}<\delta_{1}$ and $d \delta_{\gamma 2} / d \gamma>0$. If $\int_{0}^{1 / \delta_{\gamma^{2}}}(w-$ $\left.w_{1}+s_{1}\right) t \varphi(t) d t+\int_{0}^{c / w_{1}-\left(w-w_{1}\right) / w_{1} \delta_{\gamma^{2}}}\left(w_{1} t-c\right) \varphi(t) d t=0$, then $\delta_{\gamma^{2}}=\delta_{1}$ and $d \delta_{\gamma_{2}} / d \gamma=0$. If $\int_{0}^{1 / \delta_{\gamma^{2}}}\left(w-w_{1}+s_{1}\right) t \varphi(t) d t+$ $\int_{0}^{c / w_{1}-\left(w-w_{1}\right) / w_{1} \delta_{\gamma 2}}\left(w_{1} t-c\right) \varphi(t) d t<0$, then $\delta_{\gamma 2}>\delta_{1}$ and $d \delta_{\gamma_{2}} / d \gamma<0$.
Proof of Lemma 5. From (7), set

$$
\begin{aligned}
& M_{1}\left(\delta_{\gamma 1}, w\right)=(\gamma-1) \\
& \quad \cdot \int_{0}^{s_{1} /\left(w+s_{1}\right) \delta_{\gamma 1}+c /\left(w+s_{1}\right)}\left[\left(w+s_{1}\right) t-c\right] \varphi(t) d t \\
& \quad+\int_{0}^{1 / \delta_{\gamma 1}}\left(w-w_{1}+s_{1}\right) t \varphi(t) d t-c+w_{1} \mu .
\end{aligned}
$$

Then, we get

$$
\begin{aligned}
\frac{d \delta_{\gamma 1}}{d w} & =-\frac{\partial M_{1} / \partial w}{\partial M_{1} / \partial \delta_{\gamma 1}}=\frac{\int_{0}^{1 / \delta_{\gamma 1}} t \varphi(t) d t+(\gamma-1) \int_{0}^{s_{1} /\left(w+s_{1}\right) \delta_{\gamma 1}+c /\left(w+s_{1}\right)} t \varphi(t) d t .}{\left(w-w_{1}+s_{1}\right)\left(1 / \delta_{\gamma 1}^{3}\right) \varphi\left(1 / \delta_{\gamma 1}\right)+(\gamma-1)\left(s_{1}^{2} /\left(w+s_{1}\right) \delta_{\gamma 1}^{3}\right) \varphi\left(s_{1} /\left(w+s_{1}\right) \delta_{\gamma 1}+c /\left(w+s_{1}\right)\right)} \\
& >0 .
\end{aligned}
$$

Similarly, we can get $d \delta_{\gamma 1} / d s_{1}>0$ and $d \delta_{\gamma_{1}} / d c<0$. We also can get $d \delta_{\gamma_{2}} / d w>0, d \delta_{\gamma 2} / d w_{1}>0, d \delta_{\gamma 2} / d s_{1}>0$, and $d \delta_{\gamma_{2}} / d c<0$.

Proof of Theorem 6. Equation (14) shows that

$$
\begin{aligned}
& \frac{d E\left[\pi^{b}(q)\right]}{d q} \\
& =\int_{0}^{d / \delta_{\gamma i} q} p t \delta_{\gamma i} \varphi(t) d t \\
& \quad-\int_{0}^{1 / \delta_{\gamma i}}\left(w+s_{1}-w_{1}\right)\left(t \delta_{\gamma i}-1\right) \varphi(t) d t-w \\
& \quad-w_{1}\left(\mu \delta_{\gamma i}-1\right), \\
& \frac{d^{2} E\left[\pi^{b}(q)\right]}{d(q)^{2}}=-\frac{p d}{\delta_{\gamma i}^{2}(q)^{3}} \varphi\left(\frac{d}{\delta_{\gamma i} q}\right)<0 .
\end{aligned}
$$

Thus, $E\left[\pi^{b}(q)\right]$ is concave in $q$. Let $d E\left[\pi^{b}(q)\right] / d q=0$; we can derive (15).

Proof of Theorem 7. Proof of Theorem 7 is similar to the proof of Theorem 6.

\section{Conflict of Interests}

The authors declare that there is no conflict of interests regarding the publication of this paper.

\section{Acknowledgments}

The first author is supported by National Natural Science Foundation of China (nos. 71272128 and 71432003) and National Soft Science Research Program (no. 2013GXS4D145). The second author is supported by Program for New Century Excellent Talents in University (no. NCET-12-0087) and Youth Foundation for Humanities and Social Sciences of Ministry of Education of China (no. 11YJC630022).

\section{References}

[1] V. Nagali, J. Hwang, D. Sanghera et al., "Procurement Risk Management (PRM) at Hewlett-Packard company," Interfaces, vol. 38, no. 1, pp. 51-60, 2008.

[2] P. Singhal, G. Agarwal, and M. L. Mittal, "Supply chain risk management: review, classification and future research directions," International Journal of Business Science and Applied Management, vol. 6, no. 3, pp. 15-42, 2011.

[3] Y. He and J. Zhang, "Random yield risk sharing in a two-level supply chain," International Journal of Production Economics, vol. 112, no. 2, pp. 769-781, 2008.

[4] X. Li, Y. Li, and X. Cai, "Double marginalization and coordination in the supply chain with uncertain supply," European Journal of Operational Research, vol. 226, no. 2, pp. 228-236, 2013.

[5] S. Y. Tang and P. Kouvelis, "Pay-back-revenue-sharing contract in coordinating supply chains with random yield," Production and Operations Management, vol. 23, no. 12, pp. 2089-2102, 2014. 
[6] K. Inderfurth and J. Clemens, "Supply chain coordination by risk sharing contracts under random production yield and deterministic demand," OR Spectrum, vol. 36, no. 2, pp. 525556, 2014

[7] X. M. Yan and K. Liu, "An analysis of pricing power allocation in supply chains of random yield and random demand," International Journal of Information and Management Sciences, vol. 20, no. 3, pp. 415-433, 2009.

[8] N. Wan and X. Chen, "Bilateral coordination strategy of supply chain with bidirectional option contracts under inflation," Mathematical Problems in Engineering, vol. 2015, Article ID 369132, 16 pages, 2015.

[9] N. Wan and X. Chen, "Supply chain bilateral coordination with option contracts under inflation scenarios," Discrete Dynamics in Nature and Society, vol. 2015, Article ID 502021, 16 pages, 2015.

[10] K. R. MacCrimmon and D. A. Wehrung, Taking Risks: The Management of Uncertainty, Free Press, New York, NY, USA, 1996.

[11] M. E. Schweitzer and G. P. Cachon, "Decision bias in the newsvendor problem with a known demand distribution: experimental evidence," Management Science, vol. 46, no. 3, pp. 404-420, 2000.

[12] T.-H. Ho and J. Zhang, "Designing pricing contracts for boundedly rational customers: does the framing of the fixed fee matter?” Management Science, vol. 54, no. 4, pp. 686-700, 2008.

[13] I. Erev, E. Ert, and E. Yechiam, "Loss aversion, diminishing sensitivity, and the effect of experience on repeated decisions," Journal of Behavioral Decision Making, vol. 21, no. 5, pp. 575-597, 2008.

[14] D. Kahneman and A. Tversky, "Prospect theory: an analysis of decision under risk," Econometrica, vol. 47, no. 2, pp. 263-292, 1979.

[15] X. Li and Y. J. Li, "On lot-sizing problem in a random yield production system under loss aversion," Annals of Operations Research, 2014.

[16] X. Chen, G. Hao, and L. Li, "Channel coordination with a lossaverse retailer and option contracts," International Journal of Production Economics, vol. 150, pp. 52-57, 2014.

[17] C.-H. Chiu and T.-M. Choi, "Supply chain risk analysis with mean-variance models: a technical review," Annals of Operations Research, 2013.

[18] Y. J. Li, X. P. Zhen, and X. Q. Cai, “Trade credit insurance, capital constraint, and the behavior of manufacturers and banks," Annals of Operations Research, 2014.

[19] S. Karlin, "One stage models with uncertainty," in Studies in the Mathematical Theory and Production, K. J. Arrow, S. Karlin, and H. Scarf, Eds., Stanford University Press, Stanford, Calif, USA, 1958.

[20] C. A. Yano and H. L. Lee, "Lot sizing with random yields: a review," Operations Research, vol. 43, no. 2, pp. 311-334, 1995.

[21] X. Chen and Z.-J. Shen, "An analysis of a supply chain with options contracts and service requirements," IIE Transactions, vol. 44, no. 10, pp. 805-819, 2012.

[22] X. Chen, L. Li, and M. Zhou, "Buyer's pricing strategy for supply chain with warranty period-dependent demand," OmegaInternational Journal of Management Science, vol. 40, no. 6, pp. 807-816, 2012.

[23] B. Keren, "The single-period inventory problem: extension to random yield from the perspective of the supply chain," Omega, vol. 37, no. 4, pp. 801-810, 2009.
[24] X. Li, Y. Li, and X. Cai, "A note on the random yield from the perspective of the supply chain," Omega, vol. 40, no. 5, pp. 601610, 2012.

[25] C. X. Wang, "Random yield and uncertain demand in decentralised supply chains under the traditional and VMI arrangements," International Journal of Production Research, vol. 47, no. 7, pp. 1955-1968, 2009.

[26] A. Kaki, A. Salo, and S. Talluri, "Scenario-based modeling of interdependent demand and supply uncertainties," IEEE Transactions on Engineering Management, vol. 61, no. 1, pp. 101113, 2014.

[27] L. Eeckhoudt, C. Gollier, and H. Schlesinger, “The risk-averse (and prudent) newsboy," Management Science, vol. 41, no. 5, pp. 786-794, 1995.

[28] C. X. Wang and S. Webster, "The loss-averse newsvendor problem," Omega, vol. 37, no. 1, pp. 93-105, 2009.

[29] W. Liu, S. Song, and C. Wu, "Impact of loss aversion on the newsvendor game with product substitution," International Journal of Production Economics, vol. 141, no. 1, pp. 352-359, 2013.

[30] X. Chen and Q. Zhou, "Loss-averse retailer's optimal ordering policies for perishable products with customer returns," Mathematical Problems in Engineering, vol. 2015, Article ID 831796, 5 pages, 2014.

[31] X. Deng, J. Xie, and H. Xiong, "Manufacturer-retailer contracting with asymmetric information on retailer's degree of loss aversion," International Journal of Production Economics, vol. 142, no. 2, pp. 372-380, 2013.

[32] C. X. Wang and S. Webster, "Channel coordination for a supply chain with a risk-neutral manufacturer and a loss-averse retailer," Decision Sciences, vol. 38, no. 3, pp. 361-389, 2007.

[33] B. C. Giri, "Managing inventory with two suppliers under yield uncertainty and risk aversion," International Journal of Production Economics, vol. 133, no. 1, pp. 80-85, 2011.

[34] W. Liu, S. Song, and C. Wu, "The loss-averse newsvendor problem with random yield," Transactions of the Institute of Measurement and Control, vol. 36, no. 3, pp. 312-320, 2014.

[35] G. P. Cachon, "Supply chain coordination with contracts", in Handbooks in Operations Research and Management Science, A. G. de Kok and S. C. Graves, Eds., vol. 11, pp. 229-339, Elesiver Science Publishers, North-Holland, Amsterdam, The Netherlands, 2003. 


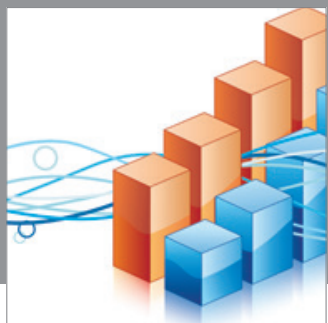

Advances in

Operations Research

mansans

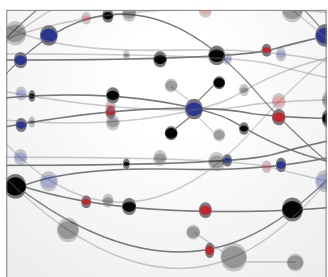

The Scientific World Journal
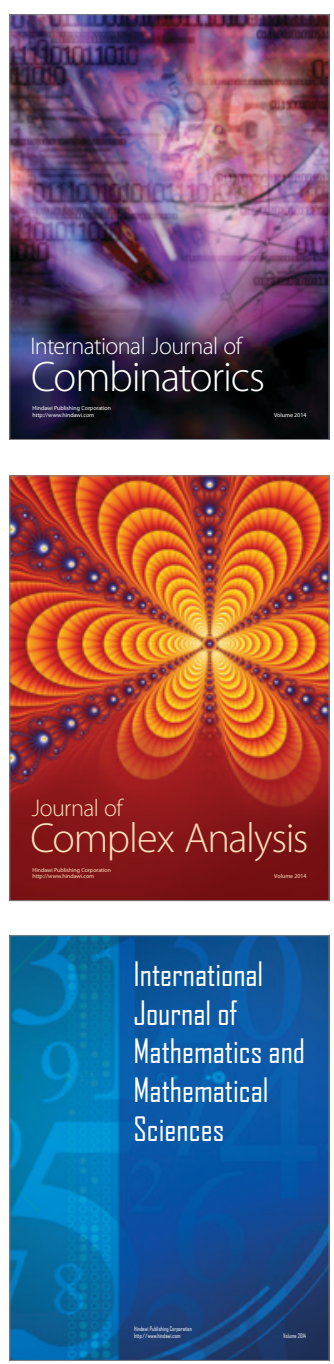
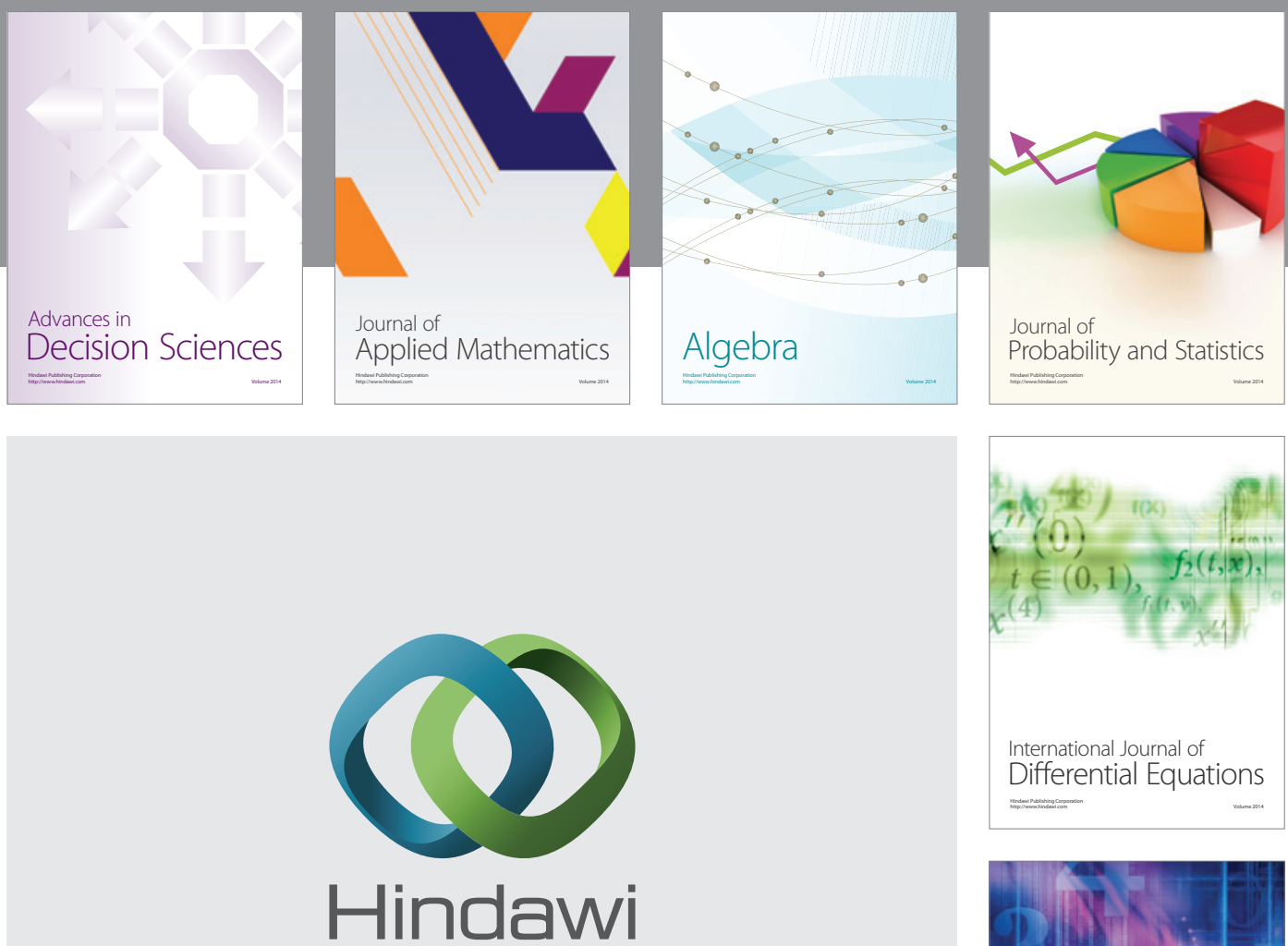

Submit your manuscripts at http://www.hindawi.com
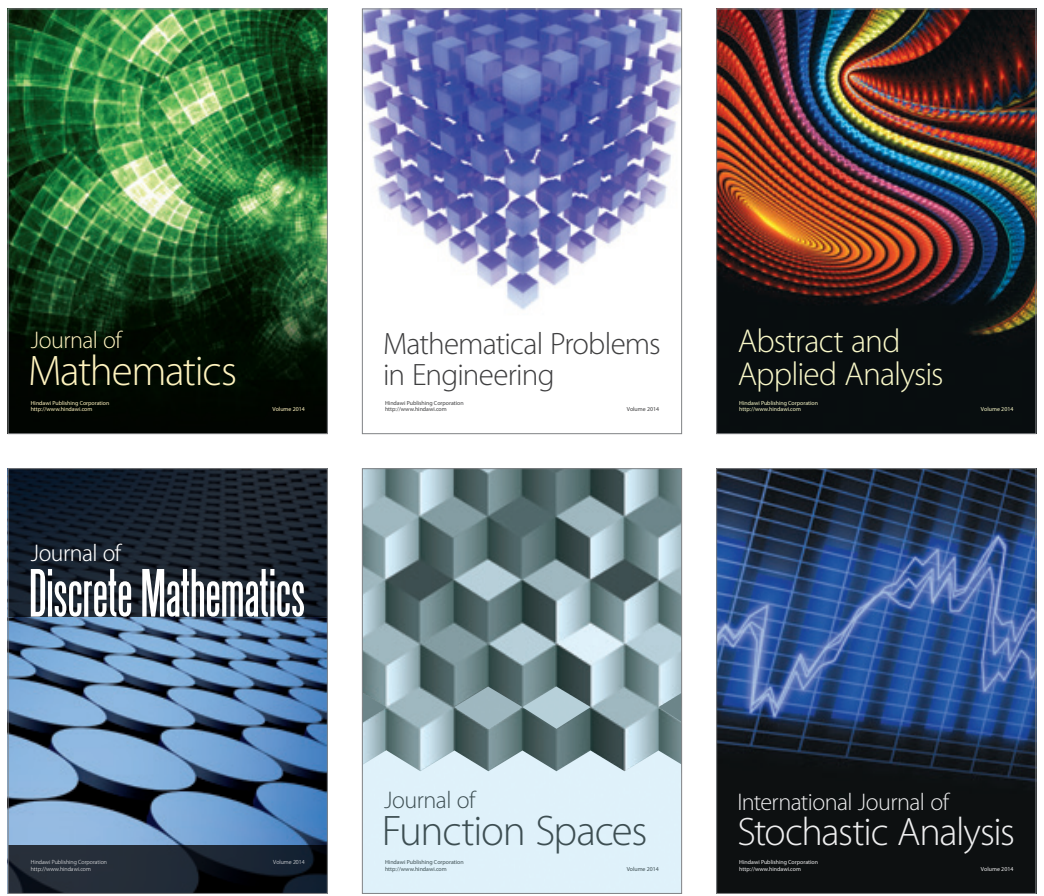

Journal of

Function Spaces



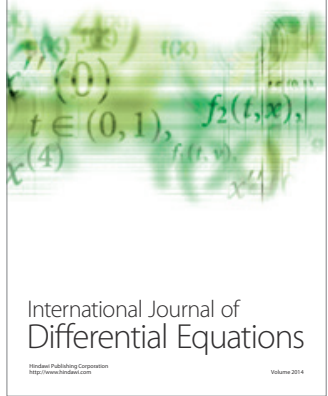
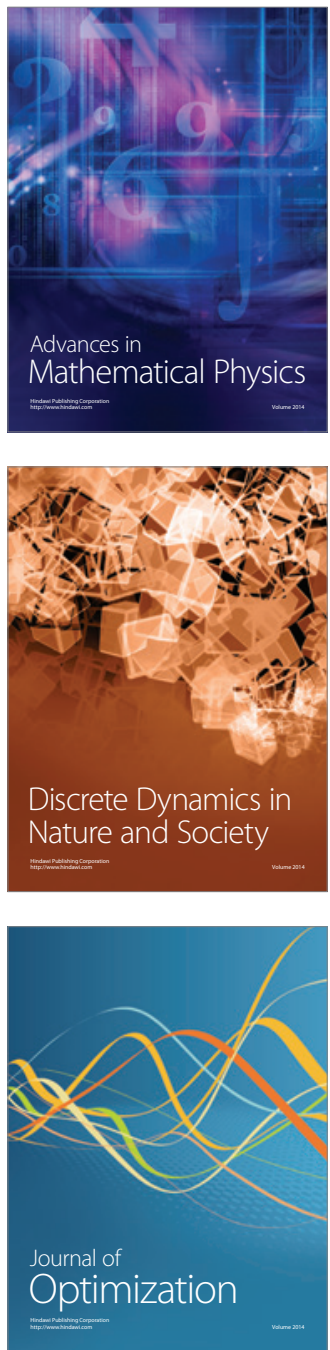